\title{
PEMBANGUNAN SISTEM PENGAIRAN DALAM UPAYA MEMENUHI KEBUTUHAN MASYARAKAT DUSUN CENGAL
}

\author{
Gatot Eka Pramonoㄹ, Siti Aminah, Rika ${ }^{2}$ \\ gatot@ft.uika-bogor.ac.id \\ Dosen Fakultas Teknik ${ }^{1}$, Mahasiswa KKN Kelompok 54 Tahun $2018^{2}$
}

\begin{abstract}
ABSTRAK
Dusun Cengal merupakan dusun yang terletak di dekat PLTA Desa Karacak. Namun pada musim kemarau masyarakat Dusun Cengal mengalami kesulitan dalam mendapatkan air untuk kebutuhan sehari-hari. Kebutuhan air per keluarga dengan jumlah dua orang anak adalah 500L-650L per hari. Oleh sebab itu untuk mengurangi kesulitan air pada masyarakat Dusun Cengal dilakukan dengan membangun sebuah penampungan air dengan panjang sekitar 2x1 meter dengan kedalaman sekitar 1,5 meter dan saluran air dengan panjang sekitar 500 meter.
\end{abstract}

\section{Kata Kunci : Cengal, Pengairan, Pembangunan}

\section{PENDAHULUAN}

Secara Geografis, Dusun Cengal merupakan sebuah dusun yang berada di wilayah Desa Karacak Kecamatan Leuwiliang Kabupaten Bogor yang berbatasan langsung dengan Desa Dahu/Barengkok dari sebelah Timur, sebelah Selatan berbatasan dengan Kampung Nanggung, sebelah Barat berbatasan dengan Kampung Kidul dan sebelah Utara berbatasan dengan Dusun Ciputih. Dusun Cengal terdiri dari 2 Rukun Warga (RW) yaitu RW 005 dan RW 006 dengan jumlah Kepala Keluarga (KK) keseluruhan adalah 550KK yang masingmasing RW terdiri dari $\pm 200 \mathrm{KK}$. Dusun Cengal memiliki luas wilayah $\pm 250 \mathrm{Ha}$ dengan kontur tanah berupa perbukitan atau pegunungan karena Dusun Cengal ini terletak di bawah kaki pegunungan.

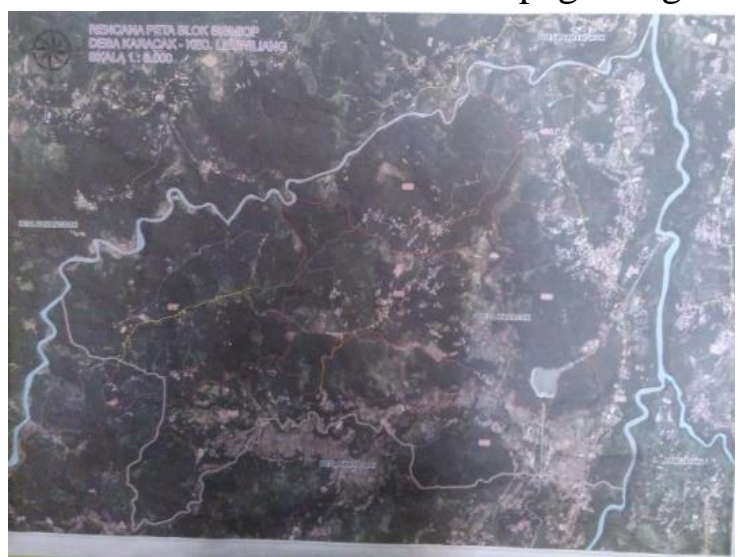

Di Dusun Cengal terdapat sungaisungai dengan air yang masih jernih dan tidak tercemar yang digunakan oleh masyarakat sebagai sumber air untuk dapat memenuhi kebutuhan sehari-hari. Sumber air terdekat yang digunakan oleh masyarakat berada sekitar 1000 meter yang terletak di bawah pedesaan. Air tersebut dialirkan ke tempat penampungan warga (toren). namun saat ini sumber air tersebut mengalami kekeringan akibat musim kemarau panjang dari bulan Juni hingga Agustus padahal Dusun Cengal berada di 
dekat PLTA. Kebutuhan air per keluarga dengan jumlah dua orang anak adalah 500L-650L per hari. Untuk tetap memenuhi kebutuhan sehari-hari, masyarakat menggunakan MCK yang letaknya cukup jauh yaitu sekitar 200-300 meter dari pemukiman warga akan tetapi hal ini masih menjadi permasalahan warga Dusun Cengal karena keterbatasan air menimbulkan persaingan dalam memperoleh air sehingga munculnya konflik kepentingan penggunaan air.

Dalam mengatasi masalah ini, masyarakat menggunakan sumber air lain yang letaknya lebih jauh yaitu sekitar 1000 meter dari sumber air yang digunakan sebelumnya. Namun

kurangnya sarana prasarana dalam sistem pengairan untuk sumber air tersebut, sehingga menghambat dalam penyebaran air yang membuat masyarakat sulit mendapatkan air. untuk kebutuhan sehari-hari.

Dari uraian di atas, program yang dilaksanakan dalam memecahkan permasalahan tersebut yaitu dengan Pembangunan Sistem Pengairan yang bertujuan untuk mempermudah masyarakat untuk memenuhi kebutuhan air.

\section{METODE PENGABDIAN}

Metode pengabdian yang dilakukan dalam program ini adalah sebagai berikut :

1. Analisa Situasi Masyarakat

Kegiatan ini dilakukan dengan pendekatan kepada masyarakat dan para tokoh masyarakat untuk mendapatkan informasi mengenai permasalahan yang ada di Dusun Cengal.

2. Menentukan Tujuan Kerja

Dari hasil analisa situasi tersebut, bertujuan untuk memberi bantuan secara materil dan non materil sehingga kebutuhan air masyarakat terpenuhi.

3. Pendekatan Sosial

Dari pendekatan sosial ini dilakukannya diskusi dengan kepala dusun dan pihak-pihak terkait mengenai masalah pengairan dengan solusi yang ditawarkan yaitu berupa penyediaan bahan-bahan yang dibutuhkan.

4. Pelaksanaan Kegiatan

Kegiatan ini dilaksanakan pada hari Rabu 29 Agustus 2018. Kegian diawali dengan breefing dengan Kepala Dusun beserta tokoh masyarakat untuk mengetahui material yang dibutuhkan dalam pembangunan sistem pengairan yaitu berupa selang yang akan dipasang dari sumber air dan ditampung di penamapungan yang berada di masjid untuk dialirkan ke rumah rumah warga.

5. Evaluasi Kegiatan Dan Hasil

Kegiatan evaluasi ini dilakukan untuk mengetahui setiap proses dalam kegiatan tersebut dan seberapa besar keberhasilan program yang dilaksanakan serta mengetahui dampak yang ditimbulkan.

\section{REALISASI PROGRAM}

Program Pembangunan Sistem Pengairan ini dilaksanakan pada hari Rabu tanggal 29 Agustus 2018 yang berlokasi di sumber air Dusun Cengal bersama Kepala Dusun beserta warga. Kegiatan yang dilaksanakan antara lain pengecekan sumber air yang memiliki jarak sekitar 1000 meter dari pemukiman warga Dusun Cengal, pemasangan saluran pengairan berupa selang yang memiliki panjang 
sekitar 500 meter dan pengecoran penampungan air yang memiliki luas sekitar 2x1 meter dengan kedalaman 1,5 meter.
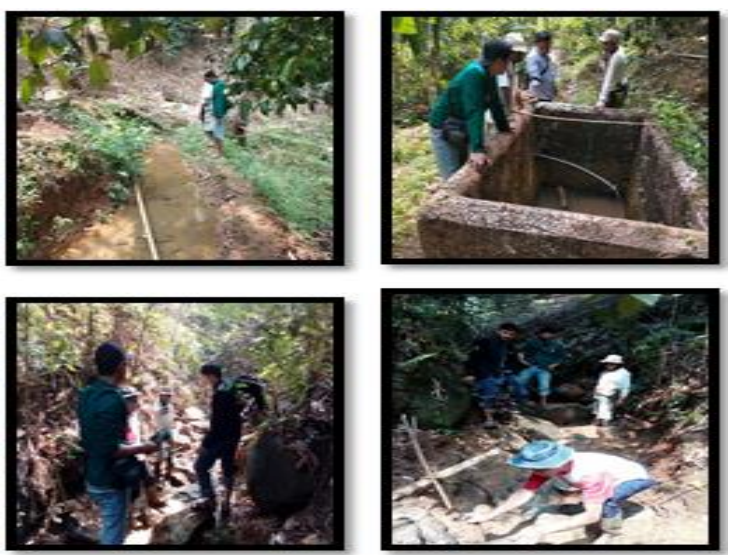

\section{Program Lain Yang Dilaksanakan}

\section{Bidang Teknik}
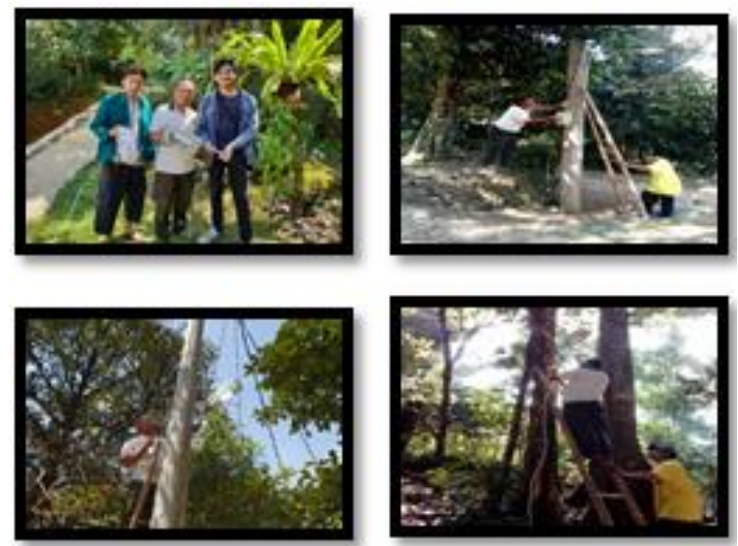

\subsection{Penerangan Jalan}

Kegiatan ini bertujuan untuk memberikan fasilitas berupa lampu penerang jalan sehingga mempermudah akses masyarakat menuju masjid terutama ketika malam hari. Kegiatan ini dilaksanakan pada hari Selasa tanggal 4 September 2018 di jalan menuju masjid Al-Muhajirin.

\section{Bidang Ekonomi}
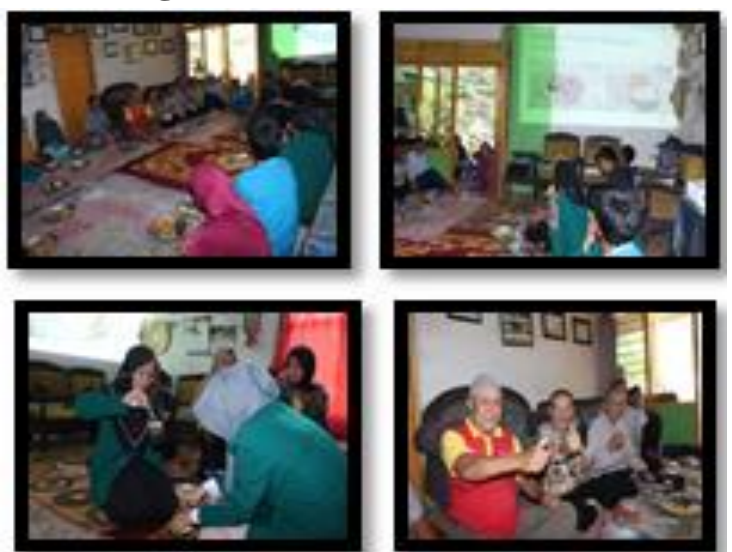

\subsection{Forum Diskusi}

Forum Diskusi yang bertemakan "Pemberdayaan Masyarakat Yang Cerdas, Aktif, Kreatif Dan Berjiwa Kewirausahaan ini dikhususkan kepada KWT (Kelompok Warga Tani) dan ibu rumah tangga karena pentingnya peran ibu dalam mengatur keuangan keluarga. Kegiatan dilaksanakan pada hari Sabtu tanggal 25Agustus 2018 di Aula Kelompok Warga Tani (KWT).

\section{Bidang Pendidikan}
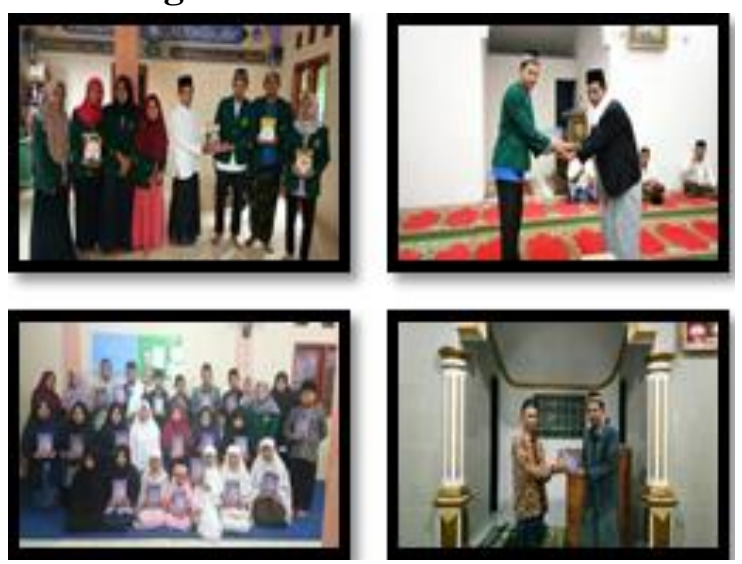

3.1 Bakti Sosial (Wakaf) Buku Islami Dan Al-Quran

Kegiatan ini berupa Wakaf dimana kami mewakafkan beberapa buku islami ke pondok pesantren Majroatussibyan yang bertujuan untuk mendukung sarana dan prasarana pendidikan dalam 
menambah ilmu keislaman serta menambah minat baca santriwan/santriwati. Selain itu, kami juga mewakafkan 40 eksampler Al-Qur'an yang ditujukan ke 3 tempat yaitu Pondok Pesantren, Masjid Al-Ihsan dan Masjid Al-Muhajirin yang bertujuan untuk mendukung kegiatan ibadah masyarakat Dusun Cengal. Kegiatan yang pertama, yaitu wakaf buku Islami yang dilaksanakan pada hari Senin tanggal 20 Agustus 2018 di Pondok Pesantren Adzkiyatunida. Kegiatan yang kedua, yaitu wakaf Al-Qur'an yang dilaksanakan pada hari Sabtu tanggal 25 Agustus 2018 di Masjid Al-Ihsan dengan jumlah Al-Qur'an 10 eksampler. Kegiatan yang ketiga, yaitu wakaf Al-Qur'an yang dilaksanakan pada hari Kamis tanggal 30 Agustus 2018 di Pondok Pesantren Adzkiyatunida dengan jumlah Al-Qur'an 20 eksampler. Kegiatan yang keempat, yaitu wakaf Al-Qur'an yang dilaksanakan pada hari Senin tanggal 3 September 2018 di Masjid Al-Muhajirin dengan jumlah Al-Qur'an 10 eksampler.
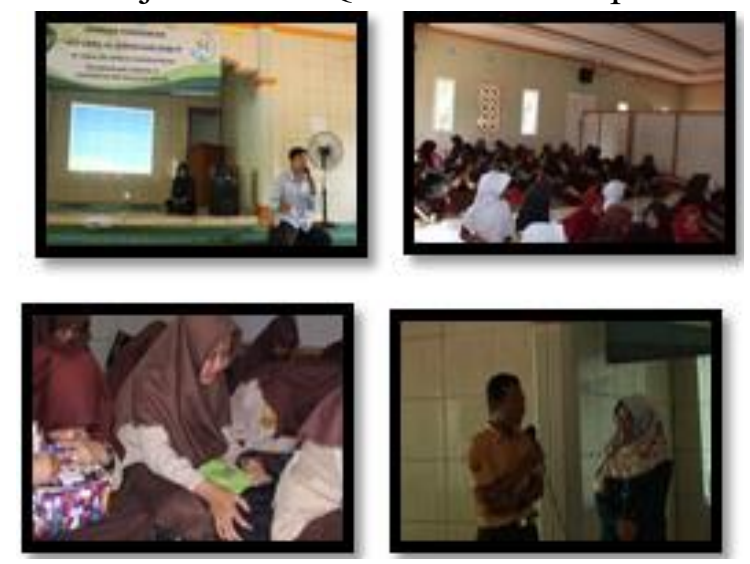

\subsection{Seminar Pendidikan}

Memberikan motivasi serta memberikan arahan agar para siswa-siswi mengetahui pentingnya pendidikan, dan memberikan motivasi agar siswa-siswi lebih giat dan semangat mencari ilmu untuk menggapai cita-cita mereka. Kegiatan ini dilaksanakan pada hari Sabtu tanggal 01 September 2018 di Masjid MTs. Mazroatussibyan.
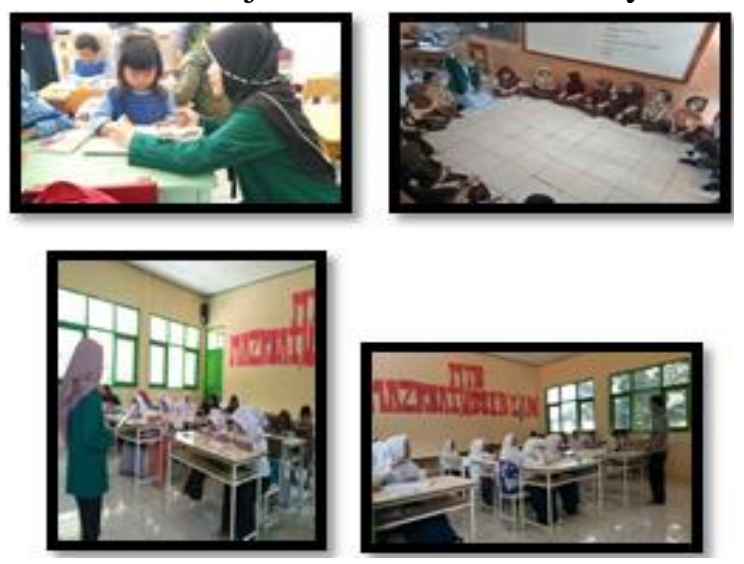

\subsection{Mengajar Di Sekolah}

Kegiatan mengajar ini bertujuan mengaplikasikan ilmu yang telah didapat dikampus dan sekaligus membantu para guru untuk mengajar siswa-siswi. Kegiatan ini dilaksanakan di 4 sekolah yaitu di RA MAzroatussibyan, SDN Cengal Sirna, Diniyah Mazroatussibyan dan MTs. Mazroatussibyan. Kegiatan ini dilaksanakan setiap hari dari pukul 07:30 WIB12:00WIB.
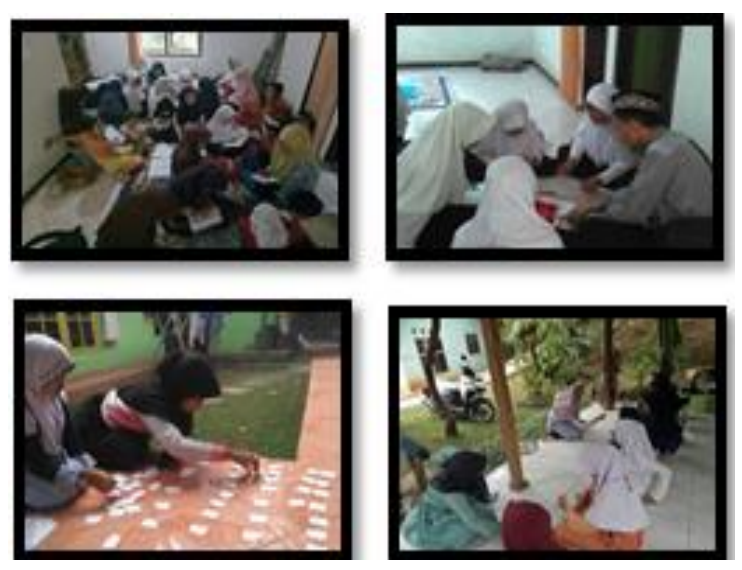

\subsection{Bimbingan Belajar}

Bimbingan belajar ini adalah kegiatan belajar mengajar untuk 
membimbing siswa-siswi sekolah dasar dalam membantu mengerjakan pekerjaan rumah dan membantu siswa-siswi dalam mengasah bakat seperti les menari. Kegiatan ini dilaksanakan setiap hari mulai pukul 16:00 WIB di Posko 54.

\section{Bidang Kesehatan}

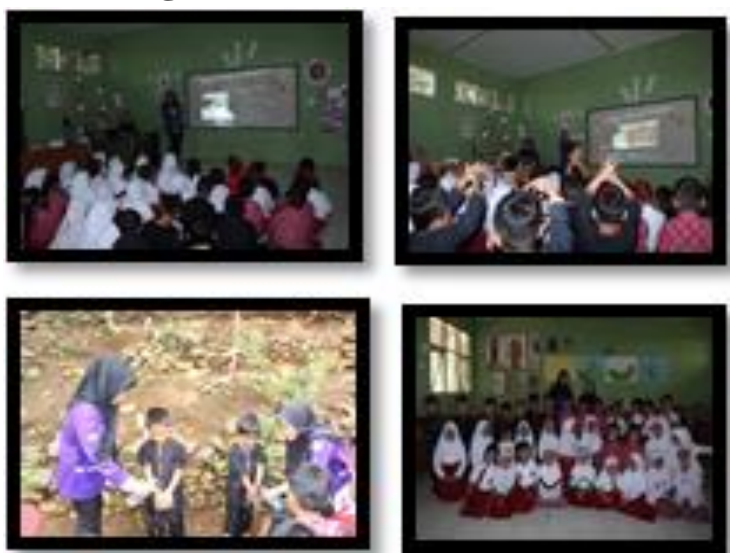

4.1 Penyuluhan PHBS Cuci Tangan

Mengajak murid sekolah dasar untuk berperilaku hidup bersih dan sehat yaitu dengan cara pengenalan cuci tangan yang baik dan benar agar murid sekolah dasar dapat mengaplikasikan dalam kehidupan sehari-hari. Kegiatan ini dilaksanakan pada hari Rabu tanggal 29 Agustus 2018 di SDN Cengal Sirna.
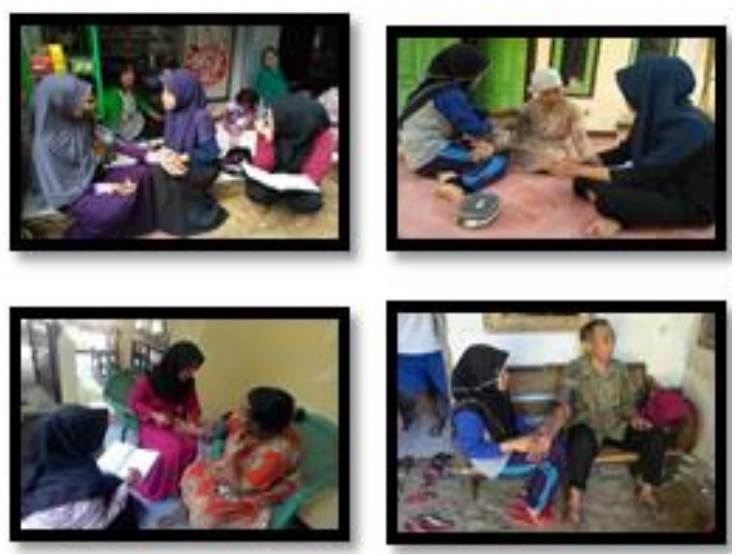

\subsection{Kunjungan Dan Tensi Lansia}

Kunjungan tensi lansia merupakan salah satu kegiatan untuk mengetahui tekanan darah pada lansia yang berusia 60 tahun ke atas sehingga lansia dapat melakukan pencegahan terhadap penyakit hipertensi. Kegiatan ini dilakukan secara continue yaitu dua minggu sekali yang bertujuan untuk mengontrol tekanan darah pada lansia. Kegiatan ini dilaksanakan pada setiap hari Jumat tanggal 10 \& 24 Agustus 2018 di RT 002 dan RT 003 Dusun Cengal.
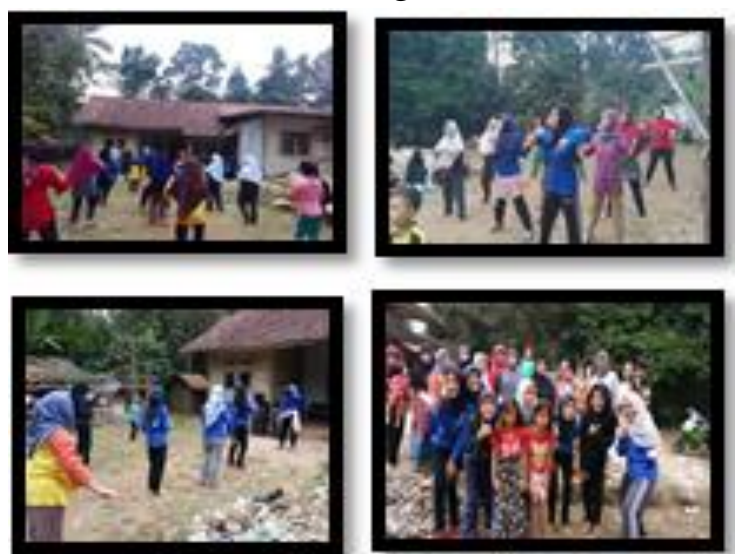

\subsection{Senam Sehat}

Senam ini adalah salah satu kegiatan untuk menciptakan masyarakat yang sehat yang dilakukan khusus untuk ibu-ibu karena ibu memiliki peran yang sangat penting dalam pemeliharaan keluarga. Kegiatan ini dilaksanakan pada setiap hari Minggu tanggal 12, 19, 26Agustus \& 2 September 2018 di halaman rumah Dusun Cengal. Menurut Eska dalam Jurnal Abdi Dosen Pemberdayaan kesehatan merupakan kegiatan penambahan pengetahuan yang diperuntukan bagi masyarakat melalui penyebaran pesan. 


\section{KESIMPULAN}

Air merupakan kebutuhan masyarakat Dusun Cengal yang bersifat esensial. Keterbatasan air menimbulkan persaingan dalam memperoleh air sehingga munculnya konflik kepentingan penggunaan air. Dalam mengatasi permasalahan tersebut dibuatlah program Pembangunan Sistem Pengairan yang bertujuan untuk mempermudah masyarakat memenuhi kebutuhan air sehari - hari.

\section{Dampak Bagi Masyarakat}

Dampak yang ditimbulkan dari program Pembangunan Sistem Pengairan yaitu tersalurkan air dengan merata ke seluruh warga Dusun Cengal dan mempermudah masyarakat dalam mendapatkan air sehingga kebutuhan masyarakat terpenuhi tanpa harus menempuh jarak yang cukup jauh.

\section{SARAN}

Dari program yang telah terwujud sekitar $40 \%$ hal ini dikarenakan kurangnya sumber daya modal dan subsidi dari pemerintah yang kurang memadai. oleh karena itu penulis berharap kepada aparatur pemerintah untuk lebih peduli kepada masyarakat akan kebutuhan air di Dusun Cengal. Selain itu perlu adanya pemerataan subsidi dari Pemerintah terkait pengairan seperti perluasan saluran air, penyaringan air dan penampungan air sehingga kebutuhan air dapat terpenuhi.

\section{REFERENSI}

Data Administrasi Dusun Cengal

Eska Perdana Prasetya (2017), Pemberdayaan Masyarakat Tentang Kesehatan, Pendidikan Dan Kreatifitas, Jurnal Abdi Dosen

Hoir, Ahsanul dkk. (2017). Pemberdayaan Menuju Masyarakat Mandiri, Sehat Dan Berwawasan Lingkungan Melalui Program Kuliah Kerja Nyata Di Desa Curahtakir Kabupaten Jember. Artikel 2017 at https://www.researchgate.net/publica tion/319650289/download diunduh pada tanggal 7 September 2018 